\title{
Antibody levels to multiple malaria vaccine candidate antigens in relation to clinical malaria episodes in children in the Kasena-Nankana district of Northern Ghana
}

Daniel Dodoo ${ }^{1 *}$, Frank Atuguba², Samuel Bosomprah ${ }^{3}$, Nana Akosua Ansah², Patrick Ansah², Helena Lamptey ${ }^{1}$ Beverly Egyir ${ }^{1}$, Abraham R Oduro², Ben Gyan ${ }^{1}$, Abraham Hodgson² and Kwadwo A Koram ${ }^{4}$

\begin{abstract}
Background: Considering the natural history of malaria of continued susceptibility to infection and episodes of illness that decline in frequency and severity over time, studies which attempt to relate immune response to protection must be longitudinal and have clearly specified definitions of immune status. Putative vaccines are expected to protect against infection, mild or severe disease or reduce transmission, but so far it has not been easy to clearly establish what constitutes protective immunity or how this develops naturally, especially among the affected target groups. The present study was done in under six year old children to identify malaria antigens which induce antibodies that correlate with protection from Plasmodium falciparum malaria.
\end{abstract}

Methods: In this longitudinal study, the multiplex assay was used to measure IgG antibody levels to 10 malaria antigens (GLURP R0, GLURP R2, MSP3 FVO, AMA1 FVO, AMA1 LR32, AMA1 3D7, MSP1 3D7, MSP1 FVO, LSA-1and EBA175RII) in 325 children aged 1 to 6 years in the Kassena Nankana district of northern Ghana. The antigen specific antibody levels were then related to the risk of clinical malaria over the ensuing year using a negative binomial regression model.

Results: IgG levels generally increased with age. The risk of clinical malaria decreased with increasing antibody levels. Except for FMPOII-LSA, $(p=0.05)$, higher IgG levels were associated with reduced risk of clinical malaria (defined as axillary temperature $\geq 37.5^{\circ} \mathrm{C}$ and parasitaemia of $\geq 5000$ parasites/ul blood) in a univariate analysis, upon correcting for the confounding effect of age. However, in a combined multiple regression analysis, only lgG levels to MSP1-3D7 (Incidence rate ratio $=0.84,[95 \% \mathrm{C.I}=0.73,0.97, \mathrm{P}=0.02])$ and AMA1 3D7 (IRR $=0.84[95 \% \mathrm{C} . \mathrm{I} .=0.74$, $0.96, P=0.01]$ ) were associated with a reduced risk of clinical malaria over one year of morbidity surveillance.

Conclusion: The data from this study support the view that a multivalent vaccine involving different antigens is most likely to be more effective than a monovalent one. Functional assays, like the parasite growth inhibition assay will be necessary to confirm if these associations reflect functional roles of antibodies to MSP1-3D7 and AMA1-3D7 in this population.

\footnotetext{
* Correspondence: DDodoo@noguchi.mimcom.org

'Department of Immunology, Noguchi Memorial Institute for Medical

Research, University of Ghana, P.O. Box LG581, Accra, Ghana

Full list of author information is available at the end of the article
} 


\section{Background}

In malaria endemic regions, clinical malaria is responsible for high morbidity and mortality in less than five year old children and pregnant women. In these regions, individuals develop a partial 'non-sterile' immunity against erythrocytic stage disease in an age and exposure dependent manner and, therefore, older individuals suffer less clinical symptoms and disease complications. Sero-epidemiological studies show three sequential phases of development of acquired immunity to malaria: first, immunity to life-threatening disease; second, immunity to symptomatic infection; and only then, can the third phase, partial immunity to parasitization be achieved $[1,2]$. Passive transfer of antibodies from malaria-immune adults have been successfully used in the treatment of malaria patients [3,4], suggesting a crucial role of antibodies in immunity to malaria.

Several studies have reported associations between levels of antibody to various malaria parasite specific antigens and reduced risk of infection [5-9]. However, as yet, the precise antigenic targets of protective immunity to malaria remain largely unknown as findings from different correlates of antibody mediated immunity studies are often conflicting in their conclusions. Thus, there is presently no single immunological correlate of protection to clinical malaria, and those described do not sufficiently account for the overall variation in susceptibility observed in a population [10].

Several antigens due to their structures and locations have been deemed of importance in inducing protective antibodies against clinical malaria of the erythrocytic stage of the parasite. These include the merozoite surface proteins (MSP1, MSP2, MSP3, etc.) and the apical membrane antigen - 1 (AMA1), EBA-175 RII and GLURP [6,7,9,9,11-13], but the mechanism of action of these antibodies in vivo remains unclear [7].

In this longitudinal study, baseline IgG levels to ten malaria vaccine candidate antigens, namely, GLURP R0, GLURP R2, MSP3 FVO, AMA1 FVO, AMA1 LR32, AMA1 3D7, MSP1 3D7, MSP1 FVO, FMP011 (LSA-1) and EBA175RII were measured by the multiplex assay in plasma samples of 1 to 6 year old children, living in a malaria endemic region and the levels related to the risk of clinical malaria estimated over a one year period. The multiplex technique which has been validated and shown to have high correlation with the traditional ELISA technique in malaria antibody measurements and which has a higher detection range [14] was the preferred assay of choice for this study. In studies involving infants and children where only small volumes of samples are obtained and antibody measurements to multiple antigens are required as in this study, the traditional ELISA method is limited by the large sample volumes required. This study was aimed at elucidating which of the antibodies to the various antigens could act individually or in a concerted manner to confer immunity to malaria in the studied population.

\section{Methods}

\section{Study site and population}

The study was conducted in the Kassena-Nankana District (KND) of the Upper East region of northern Ghana. This is a savannah region where the people are mainly subsistence farmers. There are two main seasons, a dry season from about October to April and a wet season from approximately May to October. Malaria transmission occurs throughout the year with distinct patterns during the two seasons. The estimated malaria attack rate is approximately 3.5 attacks per child per year. The district is under the Navrongo Demographic Surveillance System (NDSS), which administers a complete population census of the population every 90 days. Details of the study area and population have been published elsewhere [15]. The KND is served by the Navrongo Health Research Centre, the Navrongo War Memorial Hospital and four other health centres. The study enrolled children between the ages from 1 to 6 years in KND, who planned to remain in the district for at least the entire duration of the study (one calendar year) and their parents or guardians consented to the study.

\section{The study design}

The study enrolled 325 children between one and six years old independent of gender and with no regards to ethnicity. Children were randomly generated from the database of the NDSS and subsequently contacted in the recruitment exercise for enrolment. Only those whose parents/guardians agreed to be part of the study keeping all study required protocols were enrolled within the month of May 2004 (over a period of three weeks). These children were passively followed over one calendar year (May 2004 to May 2005) during which clinical, haematological and parasitological data were collected at the beginning of the study and every two months. Fingerprick blood samples $(0.5-1.0 \mathrm{ml})$ were used to determine haemoglobin concentrations with a Hemocue $\mathrm{Hb}$ 201 (Angelhom, Sweden) and malaria infection. Giemsastained thin and thick malaria blood films (MBFs) were done and examined by two microscopists independently for parasites. An enhanced passive follow up approach was adopted where parents and guardians were encouraged to bring study participants to the health service facilities for any perceived illness. Field workers were also placed in the community to assist parents and guardians to access medical care. During every visit to the health facility, the participants were evaluated with a morbidity questionnaire and a physical examination by 
study clinicians. A blood smear was also taken and a rapid malaria diagnostic test (DiaMed Optimal Rapid Malaria test) done. Children suffering from uncomplicated malaria were treated with chloroquine and sulphadoxine-pyrimethamine (SP) $\left(\right.$ Fansidar $\left.^{\circledR}\right)$ as the first-line drugs according to Ghana Ministry of Health policy at the time. Those with severe forms of the disease were referred for free treatment with intravenous quinine at the Navrongo War Memorial Hospital. After discharge, the subjects were physically and clinically examined by a study physician and malaria smear and haemoglobin determination were made after which the subject was allowed to resume participation in the study. Other health conditions were managed as per the prevailing guidelines of Ghana Ministry of Health.

Parasite densities were calculated by enumerating the parasites against $200 \mathrm{WBC}$. The baseline blood samples were used to measure antibody levels to 10 malaria antigens (GLURP R0, GLURP R2, MSP3 FVO, AMA1 FVO, AMA1 LR32, AMA1 3D7, MSP1 3D7, MSP1 FVO, LSA-1and EBA175RII) using the multiplex assay. The immunological data was related to the risk of clinical malaria within the study period of one year.

\section{Recombinant antigens}

The malaria antigens used in this study included a recombinant GLURP-R0 containing the conserved nonrepeat $\mathrm{N}$-terminal region, (amino acids 25-514), and GLURP-R2 (amino acids 705-1178) of the carboxy-terminal repeat region, all expressed in Escherichia coli [16] (supplied by Dr. Michael Theisen from State Serum Institute, Copenhagen). The recombinant C-terminal MSP1 42 protein of the FVO and 3D7 strains were expressed in E. coli [17]; and AMA-1 FVO (amino acids 25-545) [18], 3D7 and LR32 strains expressed in yeast Pichia pastoris, (all donated by Dr. Laura B. Martin from Malaria Vaccine Development Branch of NIAID, NIH). The EBA-175 RII expressed in yeast P. pastoris, containing amino acid residues 144 to 753 , was provided by Division of Microbiology and Infectious Diseases, (DMID) NIAID, NIH under contract NO1-AI-05421. USA. The recombinant MSP-3 of the FVO strain was expressed in E. coli, (supplied by Dr. Richard Shimp from NIAID, NIH), and the LSA-1 expressed in E. coli was donated by Dr. David E. Lanar of the Division of Malaria Vaccine Development, Walter Reed Army Institute of Research, USA.

\section{Antibody measurements}

Antigen specific IgG levels were meseasured against these antigens using the multiplex assay, a suspension array technique as described in a previous publication [14] with modifications as described below. Antigens were coupled to the microspheres using a modification of the protocol from Luminex Corp. Carboxylated microspheres or beads stock (Luminex Corp., Austin, TX) with different spectral addresses $(101,102,103$, $104,105,106,107,117,118,119$ and 120) were centrifuged at 2,000 rpm for $5 \mathrm{~min}$. The bead pellets were then dispersed by sonication and vortexing. A specified amount of the bead suspension was then centrifuged at $12000 \mathrm{rpm}$ for 2 minutes and supernatant aspirated. The pellet was washed twice in $80 \mathrm{ul}$ of activation buffer (0.1 $\mathrm{M} \mathrm{NaH}_{2} \mathrm{PO}_{4}, \mathrm{pH}$ 6.2), and then activated with $10 \mathrm{ul}$ of a $50 \mathrm{mg} / \mathrm{ml}$ solution of 1-ethyl 3-(3-dimethylaminopropyl) carbodiimide hydrochloride (EDC) and $10 \mathrm{ul}$ of a $50-\mathrm{mg} / \mathrm{ml}$ solution of sulfo- $N$-hyroxysulfosuccinimide (Sulfo NHS). The microspheres were mixed gently and incubated at room temperature (RT) ranging from $25^{\circ} \mathrm{C}$ to $28^{\circ} \mathrm{C}$, in the dark for $20 \mathrm{~min}$. The activated microspheres were then washed twice with $250 \mathrm{ul}$ of coupling buffer [0.05 $\mathrm{M}$ of 2-( $\mathrm{N}$-morpholino) ethanesulfonic acid or MES, pH 5.0] and re-suspended in $100 \mathrm{ul}$ of coupling buffer. To determine the optimal concentration of protein for coupling, 1.6, 4.0,10, 25, and $62.5 \mu \mathrm{g} / \mathrm{ml}$ of recombinant proteins and BSA were assessed. Various concentrations of the recombinant malarial antigens such as GLURP R2 at $(1.6 \mu \mathrm{g} / \mathrm{ml})$; GLURP-R0, AMA1FVO, MSP1-FVO, MSP1-3D7, LSA-1(all at $10 \mu \mathrm{g} / \mathrm{ml}$ ), MSP3 FVO, AMA1 LR32, and EBA175RII (all at $25 \mu \mathrm{g} /$ $\mathrm{ml}$ ); AMA1 3D7 at $62.5 \mu \mathrm{g} / \mathrm{ml}$ were added to the microspheres. They were then mixed gently by vortexing, followed by 20 seconds ultrasonic sonication. The total volume was adjusted to $500 \mu \mathrm{l}$ by adding the coupling buffer. The microspheres were incubated at RT in the dark for 2 hours with rotation, and then washed twice with $500 \mu \mathrm{l}$ of storage buffer (phosphate-buffered saline [PBS], $\mathrm{pH} 7.2$, containing $1 \%$ BSA, and $0.02 \%$ Tween 20 , and $0.05 \%$ sodium azide). The coupled microspheres were re-suspended in $500 \mu \mathrm{l}$ of blocking/storage buffer and stored at $4^{\circ} \mathrm{C}$ in the dark until ready for use.

\section{Multiplexed assay}

Stock suspensions of antigen-coated microspheres were thoroughly re-suspended by vortexing and sonication before use. Filter plates (Multiscreen BV; Millipore, MA) were washed with $200 \mu \mathrm{l}$ of washing buffer (PBS plus $0.05 \%$ Tween 20) and then washed with $200 \mu \mathrm{l}$ of dilution buffer (PBS plus 1\% BSA) using a vacuum manifold (Biorad Laboratories, CA, USA) to pre-wet the plates. Then, $25 \mu \mathrm{l}$ of mixed microspheres of the antigens were distributed to microtiter wells $(4,000$ microspheres/well) and $50 \mu \mathrm{l}$ of diluted plasma (1:50 and 1:2000 dilutions) was added. The plates were placed on a Microplate Shaker (Ika-schuttlar, MTS4 Labor-technik) and incubated at RT in the dark for $1 \mathrm{hr}$ at $500 \mathrm{rpm}$. The plates were washed five times with $200 \mathrm{ul}$ washing buffer. A total of $25 \mathrm{ul}$ of $5 \mathrm{ug} / \mathrm{ml}$ (1:200) of 
goat anti-human immunoglobulin G (KPL 176-1006,) was added to each well, and plates were incubated for 1 $\mathrm{hr}$ in the dark at RT on a microplate shaker. After the incubation period, plates were washed five times with washing buffer, and then $50 \mathrm{ul}$ of strepavidin phycoerythrin $(1: 800)$ was added and incubated for 30 mins at RT in the dark on a shaker. The reader (Boiplex system, Luminex Corp., Austin, TX) was programmed to read a minimum of 100 microspheres per bead region, and results were expressed as mean fluorescent intensity (MFI), which is directly proportional to antibody concentration[14]. For quality control of the assays, a pool of plasma obtained from the blood bank in Accra and predetermined to have high levels of IgG to multiple malaria antigens was included in each assay as positive control (PC). In addition, a pool of plasma from non-malaria exposed US volunteers was included as negative control (NC) in each assay. The antibody levels detected for the multiplex assay as mean fluorescent intensity (MFI) in this study varied with the different antigens used, ranging from a minimum of 25 MFI to 15, 736 MFI.

The study was reviewed and approved by the IRBs of both Noguchi Memorial Institute for Medical Research and the Navrongo Health Research Centre.

\section{Results}

\section{Pattern of Plasmodium falciparum infection and clinical} malaria in the study area

Of the total of 325 children, three hundred and fifteen had adequate samples for the immunological assays and the data generated from these was included in the analysis. Of this, 63 had at least one episode of clinical malaria during the one year period of the study and the incidence rate of clinical malaria decreased with age (Table 1). Asymptomatic P. falciparum infection was prevalent all year round; with about $60-80 \%$ study subjects carrying parasites throughout the study period (Figure 1). However, cases of clinical malaria peaked in June and dropped gradually to the lower levels typical of the low transmission season (Figure 1).

\section{Association between antibody levels, age and clinical malaria}

The sensitivity and specificity of defining clinical malaria cases may vary according to the intensity of malaraia transmission and the age of residents in malaria endemic areas [19-21]. Case definitions including parasiteamias of $2,500 / \mu$ l blood or 5,000 parasites/ul blood in addition to reported or measured fever of $\geq 37.5^{\circ} \mathrm{C}$ have been used in previous reports $[19,22]$, although for clinical practice a less strict case definition involving the history of fever is adopted. In this study involving children under seven years old in an area with sesonal, but intense malaria transmission, the case definition used was measured fever of $\geq 37.5^{\circ} \mathrm{C}$ in addition to parasitaemia at $\geq 5,000$ parasites $/ \mu \mathrm{l}$ and this was used to assess malaria specific antibody levels in relation to the risk of clinical malaria. Antibody levels in baseline samples tended to be lower in children who are negative for baseline parasitaemia and who are at higher risk to clinical malaria (Table 1). Children were considered to have a clinical malaria episode if they had axillary temperature of $\geq 37.5^{\circ} \mathrm{C}$ with a parasite density threshold greater than or equal to $5000 / \mu \mathrm{l}$.

Antibody titres to most of the antigens significantly increased with age $(0.29 \leq r \leq 0.36, p<0.0001$, Figure 2$)$, except for antibodies to LSA-1, which did not significantly correlate with age $(\mathrm{r}=0.11, \mathrm{p}=0.051)$. After adjusting for the confounding effects of age, the antibody levels against all of the antigens tested, except LSA-1, were significantly associated with reduced risk of malaria (Table 2).

\section{Table 1 Characteristics of the study population}

\begin{tabular}{|c|c|c|c|c|}
\hline Characteristics & $\begin{array}{l}\text { Cumulative incidence of } \\
\text { malaria }\end{array}$ & $\begin{array}{l}\text { Child year at } \\
\text { risk }\end{array}$ & $\begin{array}{l}\text { No. of malaria } \\
\text { episodes }\end{array}$ & $\begin{array}{l}\text { Incidence rate per } 100 \text { child year } \\
(95 \% \mathrm{Cl})\end{array}$ \\
\hline \multicolumn{5}{|l|}{ Age group } \\
\hline $12<24$ months & $52.5 \%(21 / 40)$ & 34.9 & 28 & $80(55,116)$ \\
\hline $24<36$ months & $31.5 \%(17 / 54)$ & 46.1 & 24 & $52(35,78)$ \\
\hline $36<48$ months & $12.8 \%(10 / 78)$ & 75.1 & 12 & $16(9,28)$ \\
\hline $48<60$ months & $10.3 \%(8 / 78)$ & 76.4 & 9 & $12(6,23)$ \\
\hline $60<73$ months & $10.8 \%(7 / 65)$ & 62.2 & 7 & $11(5,23)$ \\
\hline \multicolumn{5}{|c|}{$\begin{array}{l}\text { Baseline } P \text {. falciparum parasitemia } \\
\text { level }\end{array}$} \\
\hline Negative & $41.4 \%(24 / 58)$ & 52.1 & 31 & $59(42,84)$ \\
\hline Positive & $15.2 \%(39 / 257)$ & 242.7 & 49 & $20(15,27)$ \\
\hline TOTAL & $20 \%(63 / 315)$ & 295.1 & 80 & $27(22,34)$ \\
\hline
\end{tabular}

Clinical malaria is defined as history of fever or temperature $>=37.5$ and parasite density $>=5000 \mathrm{u} / \mathrm{l}$. 


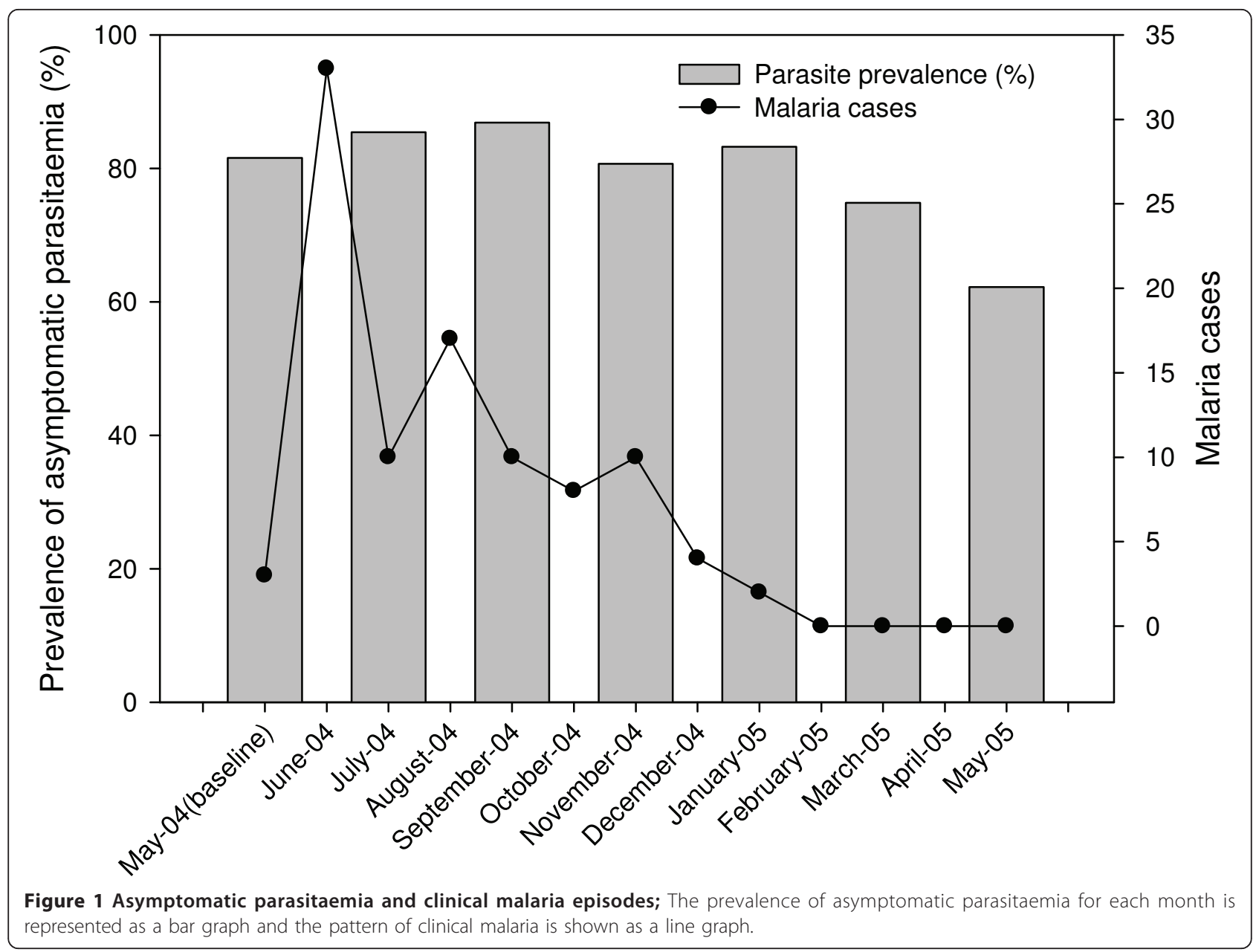

In a final model, including age and all the immunological variables that showed evidence of reduced risk to clinical malaria in the univariate analysis, only MSP13D7 $($ IRR $=0.84[95 \% \mathrm{CI}, 0.73,0.97, \mathrm{p}=0.02)]$ and AMA1-3D7 $($ IRR $=0.8[95 \%$ CI, 0.74, 0.96, p = 0.01]) were shown to be independently associated with reduced risk of clinical malaria (Table 3 ).

\section{Discussion}

The study found the persistence of asymptomatic $P$. falciparum parasitaemia in about $60-80 \%$ of the study population throughout the year. The incidence of clinical malaria however varied in parallel with the intensity of transmission and the onset of the rain as have been shown in previous studies in the same region [23]. The study area has been described as a malaria hyperendemic area with an entomological inoculation rate (EIR) of 418 infective bites and the age group used in this study was shown to have the highest prevalence of asymptomatic parasitaemia in an earlier study [24]. This could explain the persistence of asymptomatic parasitaemia year round.
The onset of rains increased vector population and might have allowed the introduction of novel parasites to which the children had no immunity from previous infection and, therefore, had the potential to cause more clinical disease [25]. Except for LSA-1 and MSP1-FVO, levels of IgG to all the antigens increased with age as shown in other studies $[8,13]$. Increasing IgG levels with age may reflect greater cumulative exposure but could also be due to older children having a more mature immune system [26]. The reason for the lack of correlation with age for anti-LSA-1 and MSP1-FVO antibodies, respectively, is unclear. It may be likely that LSA-1 is less immunogenic under the pattern of seasonal transmission in the study area in contrast to data from a study in a holoendemic region of Kenya, where infants were shown to be capable of mounting and sustaining strong anti-LSA-1 immune response in the first year of life [27], suggesting that levels of LSA antibodies might be more dependent on exposure rather than age. Interestingly, a study in Kenya [28] did not find any significant difference between antibody levels to LSA-1 in children $(\leq 8$ years old) and adults $(\geq 18$ years old) 


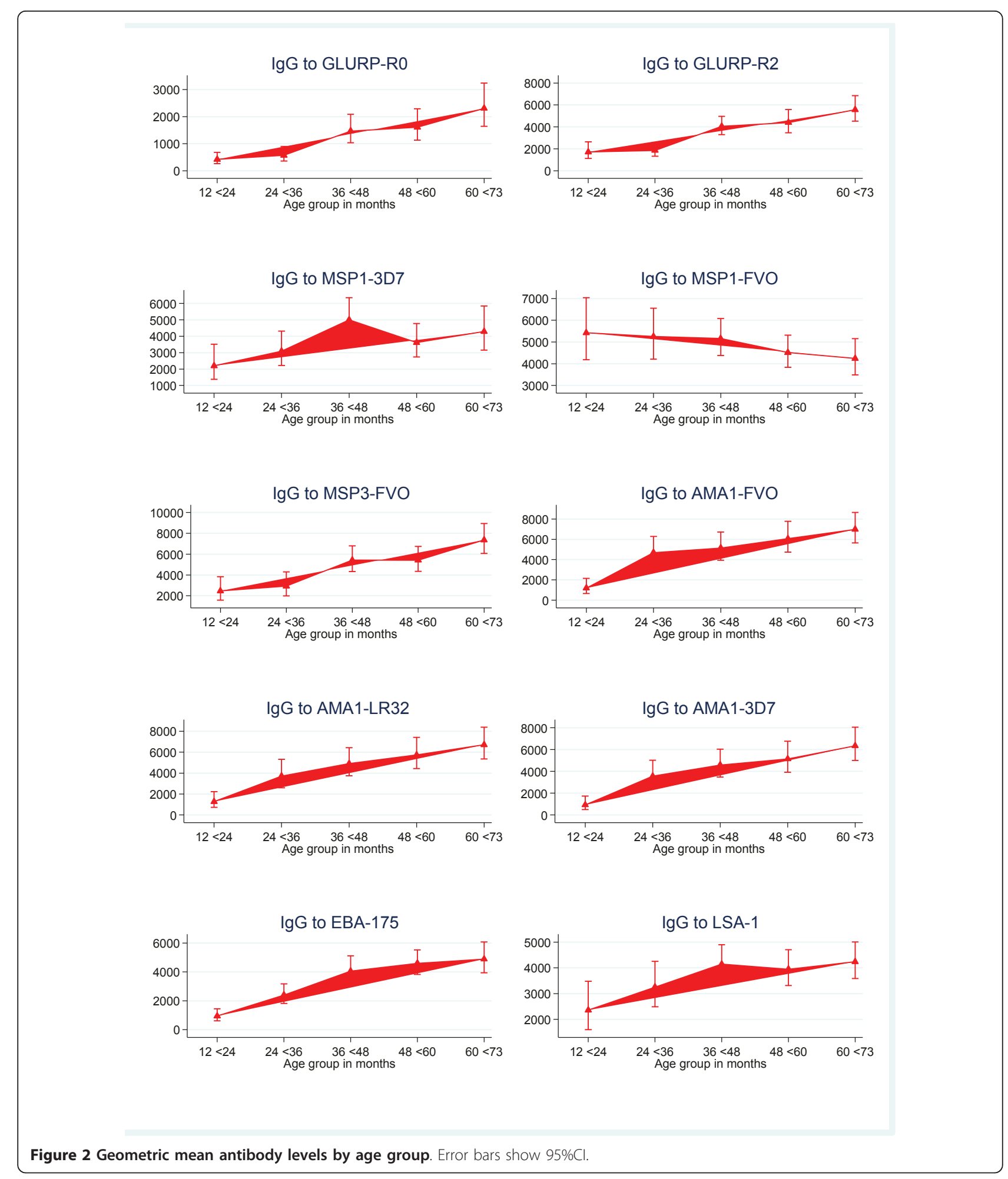

during both high and low malaria transmission seasons. The study showed a weaker correlation of IgG levels with age for MSP1-FVO compared to MSP1-3D7 implying that the 3D7 strain might be the predominant parasite in the study area but this will require parasite genotyping for confirmation. This finding is also very important as it underscores the relevance of strain specificity in design of vaccines. The relationship between malaria specific antibody response and risk of clinical malaria defined as reported or measured febrile 
Table 2 Age-adjusted IRR for the association between total IgG level with clinical malaria

\begin{tabular}{lllll}
\hline Antibody & Antigen & Crude IRR $(\mathbf{9 5} \% \mathbf{C l})$ & $\begin{array}{l}\text { IRR adjusted for age } \\
\mathbf{( 9 5 \% C l )}\end{array}$ & P-value for adjusted IRR \\
\hline IgG & GLURP-R0 & $0.76(0.67,0.86)$ & $0.85(0.75,0.96)$ & 0.01 \\
GLURP-R2 & $0.65(0.55,0.78)$ & $0.77(0.65,0.91)$ & $<0.01$ \\
MSP1-3D7 & $0.72(0.61,0.85)$ & $0.79(0.69,0.91)$ & $<0.01$ \\
MSP1-FVO & $0.81(0.63,1.06)$ & $0.73(0.58,0.93)$ & 0.06 \\
MSP3-3D7 & $0.75(0.63,0.89)$ & $0.86(0.74,1.01)$ & $<0.01$ \\
AMA1-3D7 & $0.72(0.63,0.82)$ & $0.80(0.71,0.91)$ & $<0.01$ \\
AMA1-FVO & $0.72(0.62,0.83)$ & $0.81(0.71,0.93)$ & 0.01 \\
AMA1-LR32 & $0.74(0.64,0.85)$ & $0.85(0.74,0.96)$ & 0.02 \\
EBA-175 & $0.66(0.56,0.78)$ & $0.81(0.68,0.97)$ & 0.26 \\
\hline
\end{tabular}

IRRs indicate the ratio of malaria incidence rates associated with a twofold increase in antibody level.

temperature $\geq 37.5^{\circ} \mathrm{C}$ in the presence of parasitaemia $\geq 5,000$ parasites/ $\mu \mathrm{l}$ was examined, and nine of the 10 antigens showed significant association with reduced risk of clinical malaria whereas antibodies to LSA-1 did not, which was consistent with findings from other studies $[13,26,29,30]$. A correlation between LSA-1 antibody levels and rapid parasite clearance time [31] as well as protection in children [32] has been reported, but this could not be shown in other studies [33,34]. These differences could be due to several factors including transmission intensity and the age groups of the populations studied. Further studies might be necessary to establish the role of naturally acquired LSA-1 antibodies since it's been implicated in other studies to augment ADCI to enhance liver stage merozoites clearance [1,35].

In a final model involving all the immunological variables and age, IgG to MSP1-3D7 and AMA1-3D7 were found to be independently associated with reduced risk of clinical malaria indicating their potential as candidate antigens for vaccine development. However, these findings are only associations and the antibody responses to these antigens may be surrogate markers of other malaria antigen specific immunity that were not assessed in this study. The functionality of these antibodies that correlated with protection from clinical malaria in the present study can, however, be evaluated in a functional assay such as the in vitro P. falciparum growth inhibition assay (GIA) or the antibody-dependent cellular inhibition (ADCI) assay. Unlike other immuno-epidemiological studies which are usually conducted in older individuals whose immune response mechanisms may not be similar to that of children, the focus of this study was on young children whose immune systems may be in a state of flux as they develop partial immunity to malaria. This, therefore, gives us the opportunity to study more clearly which antibodies may be associated with a reduced risk to malaria.

\section{Conclusions}

The results from this study also supports the view that a multivalent vaccine involving different antigens, such as MSP1-3D7 and AMA1-3D7, is most likely to be more effective than a monovalent one, at least in this area. These antigens can, therefore, be tested in the study site, which is under demographic surveillance and has high malaria transmission. This study also confirms the feasibility of using the multiplex assay to assess a panel of antigens with small volume of sample.

Table 3 Adjusted incidence rate ratios for immunological variables independently associated with malaria risk in the final model

\begin{tabular}{|c|c|c|c|c|}
\hline \multicolumn{2}{|c|}{ Immunological variables } & \multirow{2}{*}{$\begin{array}{l}\text { Adjusted IRR }(\mathbf{9 5} \% \mathrm{CI}) \\
0.84(0.73,0.97)\end{array}$} & \multirow{2}{*}{$\begin{array}{l}\text { Wald P-value } \\
P=0.02\end{array}$} & \multirow[t]{2}{*}{ LR test } \\
\hline MSP1-3D7 lgG & Values transformed to log base 2 & & & \\
\hline AMA1-3D7 lgG & Values transformed to log base 2 & $0.84(0.74,0.96)$ & $P=0.01$ & \\
\hline \multirow[t]{5}{*}{ Age group } & $12<24$ months & 1 & & $\chi^{2}=21.24, p<0.001$ \\
\hline & $24<36$ months & $0.94(0.44,2.01)$ & $P=0.88$ & \\
\hline & $36<48$ months & $0.33(0.14,0.77)$ & $P=0.01$ & \\
\hline & $48<60$ months & $0.21(0.08,0.51)$ & $p<0.01$ & \\
\hline & $60<73$ months & $0.24(0.09,0.66)$ & $P=0.01$ & \\
\hline
\end{tabular}

IRR indicates the ratio of malaria incidence rates associated with a twofold increase in antibody level; Parasite cut off is $5000+$. 


\section{Acknowledgements and funding}

The children and the parents/guardians of the Kassena-Nankana district of Northern Ghana are thanked for helping to make this study possible. We are grateful to the Division of Microbiology and Immunology Diseases, NIAID, $\mathrm{NIH}$ under the contract NO1-Al-05421 for providing the EBA-175 antigen used as well as NIH (Contract HHSN266200400016C) for funding the project under which this study was conducted. The staff of Navrongo Health Research Centre and the Immunology Department of Noguchi Memorial Institute are thanked for excellent field and laboratory support.

\section{Author details}

${ }^{1}$ Department of Immunology, Noguchi Memorial Institute for Medical Research, University of Ghana, P.O. Box LG581, Accra, Ghana. ${ }^{2}$ Navrongo Health Research Centre, P.O. Box 114, Navrongo, Ghana. ${ }^{3}$ Department of Biostatistics, School of Public Health, University of Ghana, P.O. Box LG 13, Accra, Ghana. ${ }^{4}$ Department of Epidemiology, Noguchi Memorial Institute for Medical Research, University of Ghana, P.O. Box LG581, Accra, Ghana.

\section{Authors' contributions}

DD designed the experiments and wrote the manuscript, FA performed and supervised field work, SB analysed the data, NAA supervised the field work, PA supervised the field work, $\mathrm{HN}$ and BE performed the experiments, ARO conducted and supervised the field work, BG designed the experiments, $\mathrm{AH}$ conceived the study, and KAK conceived the study and wrote manuscript. All authors read and approved the final manuscript.

\section{Competing interests}

The authors declare that they have no competing interests.

Received: 1 February 2011 Accepted: 1 May 2011 Published: 1 May 2011

\section{References}

1. Hay SI, Snow RW: The malaria Atlas Project: developing global maps of malaria risk. PLoS Med 2006, 3:e473.

2. Schofield L, Grau GE: Immunological processes in malaria pathogenesis. Nat Rev Immunol 2005, 5:722-735.

3. Cohen S, Mcgregor IA, Carrington S: Gamma-globulin and acquired immunity to human malaria. Nature 1961, 192:733-737.

4. Sabchareon A, Burnouf T, Ouattara D, Attanath P, Bouharoun-Tayoun $H_{\text {, }}$ Chantavanich P, Foucault C, Chongsuphajaisiddhi T, Druilhe P: Parasitologic and clinical human response to immunoglobulin administration in falciparum malaria. Am J Trop Med Hyg 1991, 45:297-308.

5. Polley SD, Mwangi T, Kocken $C H$, Thomas AW, Dutta S, Lanar DE, Remarque E, Ross A, Williams TN, Mwambingu G, Lowe B, Conway DJ Marsh K: Human antibodies to recombinant protein constructs of Plasmodium falciparum Apical Membrane Antigen 1 (AMA1) and their associations with protection from malaria. Vaccine 2004, 23:718-728.

6. Theisen M, Soe S, Oeuvray C, Thomas AW, Vuust J, Danielsen S, Jepsen S, Druilhe P: The glutamate-rich protein (GLURP) of Plasmodium falciparum is a target for antibody-dependent monocyte-mediated inhibition of parasite growth in vitro. Infect Immun 1998, 66:11-17.

7. Courtin D, Oesterholt M, Huismans H, Kusi K, Milet J, Badaut C, Gaye O, Roeffen W, Remarque EJ, Sauerwein R, Garcia A, Luty AJ: The quantity and quality of African children's IgG responses to merozoite surface antigens reflect protection against Plasmodium falciparum malaria. PLoS One 2009, 4:e7590.

8. Dodoo D, Aikins A, Kusi KA, Lamptey H, Remarque E, Milligan P, Bosomprah S, Chilengi R, Osei YD, Akanmori BD, Theisen M: Cohort study of the association of antibody levels to AMA1, MSP119, MSP3 and GLURP with protection from clinical malaria in Ghanaian children. Malar J 2008, 7:142.

9. Osier FH, Fegan G, Polley SD, Murungi L, Verra F, Tetteh KK, Lowe B, Mwangi T, Bull PC, Thomas AW, Cavanagh DR, McBride JS, Lanar DE, Mackinnon MJ, Conway DJ, Marsh K: Breadth and magnitude of antibody responses to multiple Plasmodium falciparum merozoite antigens are associated with protection from clinical malaria. Infect Immun 2008, 76:2240-2248

10. Mackintosh CL, Beeson JG, Marsh K: Clinical features and pathogenesis of severe malaria. Trends Parasitol 2004, 20:597-603.

11. Fowkes FJ, Richards JS, Simpson JA, Beeson JG: The relationship between anti-merozoite antibodies and incidence of Plasmodium falciparum malaria: A systematic review and meta-analysis. PLoS Med 2010, 7 e1000218.

12. Okenu DM, Riley EM, Bickle QD, Agomo PU, Barbosa A, Daugherty JR, Lanar DE, Conway DJ: Analysis of human antibodies to erythrocyte binding antigen 175 of Plasmodium falciparum. Infect Immun 2000, 68:5559-5566.

13. Oeuvray C, Theisen M, Rogier C, Trape JF, Jepsen S, Druilhe P: Cytophilic immunoglobulin responses to Plasmodium falciparum glutamate-rich protein are correlated with protection against clinical malaria in Dielmo, Senegal. Infect Immun 2000, 68:2617-2620

14. Fouda GG, Leke RF, Long C, Druilhe P, Zhou A, Taylor DW, Johnson AH: Multiplex assay for simultaneous measurement of antibodies to multiple Plasmodium falciparum antigens. Clin Vaccine Immunol 2006, 13:1307-1313.

15. Osafo-Addo AD, Koram KA, Oduro AR, Wilson M, Hodgson A, Rogers WO: HLA-DRB $1 * 04$ allele is associated with severe malaria in northern Ghana. Am J Trop Med Hyg 2008, 78:251-255.

16. Theisen M, Vuust J, Gottschau A, Jepsen S, Hogh B: Antigenicity and immunogenicity of recombinant glutamate-rich protein of Plasmodium falciparum expressed in Escherichia coli. Clin Diagn Lab Immunol 1995, 2:30-34.

17. Malkin E, Long CA, Stowers AW, Zou L, Singh S, MacDonald NJ, Narum DL, Miles AP, Orcutt AC, Muratova O, Moretz SE, Zhou H, Diouf A, Fay M, Tierney E, Leese P, Mahanty S, Miller LH, Saul A, Martin LB: Phase 1 study of two merozoite surface protein 1 (MSP1(42)) vaccines for Plasmodium falciparum malaria. PLoS Clin Trials 2007, 2:e12.

18. Roestenberg $\mathrm{M}$, Remarque $\mathrm{E}$, de Jonge $\mathrm{E}$, Hermsen $\mathrm{R}$, Blythman $\mathrm{H}$, Leroy $\mathrm{O}$, Imoukhuede E, Jepsen S, Ofori-Anyinam O, Faber B, Kocken CH, Arnold M, Walraven V, Teelen K, Roeffen W, de Mast Q, Ballou WR, Cohen J, Dubois MC, Ascarateil S, van d, Thomas A, Sauerwein R: Safety and immunogenicity of a recombinant Plasmodium falciparum AMA1 malaria vaccine adjuvanted with Alhydrogel, Montanide ISA 720 or AS02. PLOS One 2008, 3:e3960

19. Rogers WO, Atuguba F, Oduro AR, Hodgson A, Koram KA: Clinical case definitions and malaria vaccine efficacy. J Infect Dis 2006, 193:467-473.

20. Mmbando BP, Lusingu JP, Vestergaard LS, Lemnge MM, Theander TG, Scheike TH: Parasite threshold associated with clinical malaria in areas of different transmission intensities in north eastern Tanzania. BMC Med Res Methodol 2009, 9:75

21. Smith $T$, Schellenberg JA, Hayes R: Attributable fraction estimates and case definitions for malaria in endemic areas. Stat Med 1994, 13:2345-2358.

22. Dodoo D, Theander TG, Kurtzhals JA, Koram K, Riley E, Akanmori BD, Nkrumah FK, Hviid L: Levels of antibody to conserved parts of Plasmodium falciparum merozoite surface protein 1 in Ghanaian children are not associated with protection from clinical malaria. Infect Immun 1999, 67:2131-2137.

23. Koram KA, Owusu-Agyei S, Utz G, Binka FN, Baird JK, Hoffman SL, Nkrumah FK: Severe anemia in young children after high and low malaria transmission seasons in the Kassena-Nankana district of northern Ghana. Am J Trop Med Hyg 2000, 62:670-674.

24. Koram KA, Owusu-Agyei S, Fryauff DJ, Anto F, Atuguba F, Hodgson A, Hoffman SL, Nkrumah FK: Seasonal profiles of malaria infection, anaemia, and bednet use among age groups and communities in northern Ghana. Trop Med Int Health 2003, 8:793-802.

25. Ofori MF, Dodoo D, Staalsoe T, Kurtzhals JA, Koram K, Theander TG, Akanmori BD, Hviid L: Malaria-induced acquisition of antibodies to Plasmodium falciparum variant surface antigens. Infect Immun 2002, 70:2982-2988

26. Nebie I, Diarra A, Ouedraogo A, Soulama I, Bougouma EC, Tiono AB, Konate AT, Chilengi R, Theisen M, Dodoo D, Remarque E, Bosomprah S, Milligan P, Sirima SB: Humoral responses to Plasmodium falciparum blood-stage antigens and association with incidence of clinical malaria in children living in an area of seasonal malaria transmission in Burkina Faso, West Africa. Infect Immun 2008, 76:759-766.

27. Zhou Z, Xiao L, Branch OH, Kariuki S, Nahlen BL, Lal AA: Antibody responses to repetitive epitopes of the circumsporozoite protein, liver stage antigen-1, and merozoite surface protein-2 in infants residing in a Plasmodium falciparum-hyperendemic area of western Kenya. XIII. Asembo Bay Cohort Project. Am J Trop Med Hyg 2002, 66:7-12.

28. John CC, Ouma JH, Sumba PO, Hollingdale MR, Kazura JW, King CL: Lymphocyte proliferation and antibody responses to Plasmodium 
falciparum liver-stage antigen-1 in a highland area of Kenya with seasonal variation in malaria transmission. Am J Trop Med Hyg 2002, 66:372-378.

29. Ohas EA, Adams JH, Waitumbi JN, Orago AS, Barbosa A, Lanar DE, Stoute JA: Measurement of antibody levels against region II of the erythrocyte-binding antigen 175 of Plasmodium falciparum in an area of malaria holoendemicity in western Kenya. Infect Immun 2004, 72:735-741.

30. Perraut R, Diatta B, Marrama L, Garraud O, Jambou R, Longacre S, Krishnegowda G, Dieye A, Gowda DC: Differential antibody responses to Plasmodium falciparum glycosylphosphatidylinositol anchors in patients with cerebral and mild malaria. Microbes Infect 2005, 7:682-687.

31. Luty AJ, Lell B, Schmidt-Ott R, Lehman LG, Luckner D, Greve B, Matousek P, Herbich K, Schmid D, Ulbert S, Migot-Nabias F, Dubois B, Deloron P, Kremsner PG: Parasite antigen-specific interleukin-10 and antibody reponses predict accelerated parasite clearance in Plasmodium falciparum malaria. Eur Cytokine Netw 1998, 9:639-646.

32. Migot-Nabias F, Deloron P, Ringwald P, Dubois B, Mayombo J, Minh TN, Fievet $N$, Millet $P$, Luty A: Immune response to Plasmodium falciparum liver stage antigen-1: geographical variations within Central Africa and their relationship with protection from clinical malaria. Trans $R$ Soc Trop Med Hyg 2000, 94:557-562.

33. John CC, Zickafoose JS, Sumba PO, King CL, Kazura JW: Antibodies to the Plasmodium falciparum antigens circumsporozoite protein, thrombospondin-related adhesive protein, and liver-stage antigen 1 vary by ages of subjects and by season in a highland area of Kenya. Infect Immun 2003, 71:4320-4325.

34. Kurtis JD, Lanar DE, Opollo M, Duffy PE: Interleukin-10 responses to liverstage antigen 1 predict human resistance to Plasmodium falciparum. Infect Immun 1999, 67:3424-3429.

35. Kurtis JD, Hollingdale MR, Luty AJ, Lanar DE, Krzych U, Duffy PE: Preerythrocytic immunity to Plasmodium falciparum: the case for an LSA-1 vaccine. Trends Parasitol 2001, 17:219-223.

doi:10.1186/1475-2875-10-108

Cite this article as: Dodoo et al: Antibody levels to multiple malaria vaccine candidate antigens in relation to clinical malaria episodes in children in the Kasena-Nankana district of Northern Ghana. Malaria Journal 2011 10:108.

\section{Submit your next manuscript to BioMed Central and take full advantage of:}

- Convenient online submission

- Thorough peer review

- No space constraints or color figure charges

- Immediate publication on acceptance

- Inclusion in PubMed, CAS, Scopus and Google Scholar

- Research which is freely available for redistribution

Submit your manuscript at www.biomedcentral.com/submit
Biomed Central 